\title{
Conflictos y posibilidades de los escritores en el exilio. La discusión entre Émile Cioran y Witold Gombrowicz
}

\author{
a) \\ Nicolás Hochman ** \\ Recibido: 15 de agosto \\ Aprobado: 17 de noviembre
}

\begin{abstract}
Resumen
El artículo analiza las respuestas que el escritor polaco Witold Gombrowicz (exiliado en Argentina entre 1939 y 1963), dio al filósofo rumano Émile Cioran, quien en 1953 publicó "Ventajas y desventajas del exilio", un provocativo ensayo en el cual habla acerca de los escritores en el exilio. El texto motivó un interesante debate por parte del polaco, que aunque no llegó a prosperar, es muy simbólico de la situación de la época. Para estudiar esto nos valemos de las apreciaciones que Gombrowicz consigna en su Diario (publicado por la revista polaca Kultura), que con los años se convirtió en una fuente invalorable, no sólo para estudiar su vida y obra, sino también el clima de época y los análisis de exilio en general.
\end{abstract}

Palabras clave: Witold Gombrowicz, Émile Cioran, exilio, escritores exiliados, patria.

* El artículo es parte de una investigación mayor sobre "Las formas del exilio", y hace parte del proceso de escritura de la tesis doctoral del autor, desarrollada en la Universidad de Buenos Aires bajo la dirección del Dr. Omar Acha y el apoyo de una beca de CONICET.

** Profesor y Licenciado en Historia por la Universidad Nacional de Mar del Plata. Doctorando en Ciencias Sociales por la UBA. Becario Tipo I de CONICET. Correo electrónico: hochmanicolas@yahoo.com.ar 


\title{
Conflicts and Possibilities of Exiled Writers: Discussion between Émile Cioran and Witold Gombrowicz
}

\begin{abstract}
This article analyzes the answers the Polish writer Witold Gombrowicz (exiled in Argentina between 1939 and 1963) gave to the Romanian philosopher Emile Cioran who published "Advantages and Disadvantages of Exile" in 1953; an essay where he writes about writers in exile. The text promoted an interesting discussion by the Polish writer. Although the discussion was not successfully accepted, it was a very symbolic theme about the situation at that time. For this study, we look for support in Gombrowicz's statements in his Diary (published by the Polich journal Kultura) which became an priceless source as time passed, not only for studying his life and work, but also the environment of that period and the analysis made to exile in general.

Key words: Witold Gombrowicz; Émile Cioran; exile; exiled writers; motherland.
\end{abstract}




\section{Introducción}

Witold Gombrowicz fue un escritor polaco que, exiliado en 1939, se instaló en Argentina hasta 1963, para luego retornar a Europa: primero Alemania, luego Francia, pero nunca más a Polonia. Durante los años que vivió fuera de su patria, dedicó una gran cantidad de páginas a escribir un diario, a partir de 1953, que era publicado por la revista Kultura, destinada a otros polacos, también exiliados. En su Diario (Gombrowicz, 2005) aparecen menciones de su vida cotidiana, eventos sociales, teorizaciones sobre los temas más diversos, críticas literarias, opiniones sobre la música clásica, y todas esas cuestiones que suelen presentarse en este tipo de obras, que aunque pretenden ser íntimas y más auténticas que otras publicaciones de un autor, suelen estar atravesadas por los mismos componentes de ficción y represión que novelas, cuentos, ensayos y demás.

El objetivo de este artículo es tan simple como concreto: analizar las respuestas que Gombrowicz esgrime contra un texto de Émile Cioran aparecido en 1953, donde el filósofo rumano hacía una crítica mordaz, cínica e irónica sobre el comportamiento de los escritores exiliados. Esto tiene un interés que puede dividirse en dos partes: por un lado, la que atañe a los estudiosos de la vida y obra de Gombrowicz, que con el correr de los años aumentan ampliamente; por otro lado, la cuestión permite volver a problematizar algunas consideraciones en torno al exilio, un tema que pareciera no sólo no agotarse con el paso del tiempo, sino que cobra nuevas significaciones y permite pensar las experiencias individuales desde nuevas perspectivas.

\section{Metodología}

Este artículo se desprende de una investigación mayor, que tiene como objetivo la redacción de una Tesis de Doctorado por la Universidad de Buenos Aires, cuyo título es "Las formas del exilio. Las experiencias de Witold Gombrowicz, Osvaldo Soriano y Fabio Morábito". A partir de la búsqueda, selección y análisis de bibliografía teórica que nos permitiera abordar el concepto de exilio, y también de aquellas categorías analíticas que fueran útiles para complementar y confrontar su estudio, hicimos un relevamiento de algunas fuentes históricas que nos permitieran contextualizar los períodos a los que pertenecen los tres escritores seleccionados, junto con bibliografía específica de carácter más empírico y/o descriptivo. Esto nos permitió centrar la metodología en el análisis textual y discursivo del corpus seleccionado de cada uno de los autores, como el que aparece en este texto, representativo no solamente del pensamiento de Witold Gombrowicz, sino también sintomático de una época, en la que el exilio se convirtió en un concepto difícil de abordar, polisémico, propenso a debates muy estimulantes.

\section{El enojo de Gombrowicz}

Gombrowicz no comienza con su diario inmediatamente después de haber llegado a la Argentina, sino que hay que pensar que cuando lo hace, en 1953, llevaba catorce años viviendo fuera de Polonia, que es un plazo más que válido para haber reflexionado sobre su exilio y hacer algo en consecuencia. Por supuesto, catorce años podrían no alcanzar para terminar de elaborar la experiencia traumática (podría no alcanzar toda la vida), pero podemos intuir que todo ese tiempo no fue en vano, que muchas cosas habrán cambiado en su psiquis y su forma de afrontar la realidad.

Es 1953, y a pedido de Jerzy Giedroyc, director de la revista Kultura, Gombrowicz responde a un artículo publicado por Émile Cioran, "Ventajas y desventajas del exilio", cuya esencia sería retomada en La tentación de existir, publicado en Francia 1972 (Cioran, 1973). Por supuesto, el texto del rumano no iba dirigido al polaco, y probablemente ni siquiera supiera quién era él, pero Gombrowicz adhiere a la causa de una manera militante, y se lo toma como algo personal. Para iniciar la discusión y relativizar a Cioran, Gombrowicz comienza por hablar de los distintos tipos de 
exilio, y cita a Rimbaud, Norwid, Kakfa y Słowacki. A partir de ellos elabora la primera parte de su argumento, en el que comienza suponiendo que ninguno de estos autores se horrorizaría demasiado con la visión de la clase de infierno que representa el exilio, tal como lo ve Cioran. Explica Gombrowicz:

Es desagradable no tener lectores, muy desagradable no poder editar las propias obras, no es nada divertido ser desconocido, resulta fastidioso verse privado de la ayuda de ese mecanismo que empuja hacia arriba, hace propaganda y organiza la fama..., pero el arte está cargado de soledad y autosuficiencia, encuentra su satisfacción y su razón de ser en sí mismo. ¿La Patria? Pero si cada uno de los hombres célebres, precisamente a causa de la celebridad, ha sido extranjero hasta en su propia casa. ¿Los lectores? Pero si ellos jamás han escrito 'para' los lectores. Homenajes, éxito, renombre, fama: pero si precisamente se hicieron famosos porque se valoraban más a sí mismos que a su éxito. (Gombrowicz, 2005, pp. 68-69)

La gran pregunta es: ¿Gombrowicz habla de Rimbaud, Norwid, Kakfa y Słowacki, o está hablando de sí mismo? En todo caso, si realmente está pensando en esos cuatro autores (referentes para él), pareciera que lo hace para poder transmitir su propia experiencia, sus preocupaciones más actuales. Y lo que refleja el argumento es una posición tomada al respecto: el escritor no necesita ni de los lectores ni de la sociedad ni de la patria ni de los mecanismos de mercado para poder escribir, para poder ser. "El arte está cargado de soledad y autosuficiencia" no es una explicación científica ni objetiva, sino una afirmación que tiende a la autosugestión, a la justificación. Con ella, Gombrowicz le cuenta a su público que él está más allá de todo eso, y que precisamente esa falta es lo que le permite crecer y desarrollarse, lo que le permite hallar "su satisfacción y su razón de ser en sí mismo". El goce aparece así como motor de su experiencia (Grinberg, 1984; Schwarcz, 1999), como se puede ver, también, pocos renglones más adelante:
También me gustaría recordar a Cioran que no solamente el arte en el exilio, sino todo arte en general, está en estrecha relación con la descomposición, nace de la decadencia, es la transformación de la enfermedad en salud. (Gombrowicz, 2005, p. 69)

Si lo pensamos desde un punto de vista dialéctico, desde un Hegel gombrowicziano, el que puede leerse en su Curso de Filosofía en seis horas y cuarto (Gombrowicz, 1997; Castillo, 2010, pp. 21 28), la cosa tiene mucho sentido: Gombrowicz necesita enfermarse para poder estar sano. De hecho, no hay otra manera de estar bien, sin antes estar mal. El bienestar es posible solamente si hay malestar. La composición nace de la descomposición, el progreso de la decadencia, la salud de la enfermedad. Por supuesto, podríamos argumentar que la historia enseña otra cosa, que el mundo no siempre funciona con ese mecanismo binario, pero lo que Gombrowicz quiere transmitir con eso no es un planteo filosófico, sino más bien un posicionamiento político, ideológico, que legitime su exilio, su obra y sus excentricidades:

Cioran nos cuenta cómo perece el escritor separado de su sociedad. Pero este escritor jamás ha existido verdaderamente: es un embrión de escritor.

A mí más bien me parece que -teóricamente hablando y dejando aparte las dificultades materiales- esta sumersión en el mundo que es la emigración debería constituir un extraordinario estímulo para la literatura.

He aquí la elite de un país expulsada al extranjero. Puede pensar, sentir, escribir desde fuera. Toma distancias. Consigue una extraordinaria libertad espiritual. Se rompen todas las ataduras. Se puede ser mucho más uno mismo. En el caos general se relajan las formas reinantes hasta ahora, se puede encarar el futuro de un modo más decidido. (Gombrowicz, 2005, p. 70)

Aquí el argumento se complica un poco. Nuevamente, ¿de quién está hablando Gombro- 
wicz? Si es de los cuatro escritores citados antes, no parece que la idea de una elite expulsada al extranjero se sostenga. El caso de Słowacki puede catalogarse como tal, pero ni Norwid, ni Rimbaud, ni Kakfa sufrieron expulsiones semejantes. Y si, como podemos suponer, Gombrowicz está hablando de sí mismo, podríamos cuestionar que alguien lo haya expulsado de Polonia, e inclusive que fuera parte de la elite literaria polaca, por lo menos al momento de exiliarse (Hochman, 2011). ¿Por qué entonces sigue esta línea argumental? Probablemente porque es consecuente con la posición que adopta desde el momento en que llega a la Argentina: mostrarse como una víctima que, pese a todas las complicaciones e inadecuaciones del medio, logra no solamente sobrevivir, sino, además ser exitoso, mucho más de lo que hubiera podido serlo en Polonia, en un contexto teóricamente adecuado y mucho más simple. Porque, podemos intuir, no existían presiones materiales concretas que impidieran a Gombrowicz ser un gran escritor en su espacio original.

(Los escritores) No rugen porque... porque, ante todo, son demasiado libres. $\mathrm{El}$ arte requiere estilo, orden disciplina. Cioran resalta con razón el peligro de una excesiva separación, de una excesiva libertad. Todo aquello a lo que estaban ligados y que les ataba: la patria, la ideología, la política, el grupo, el programa, la fe, el ambiente, todo eso ha desaparecido en la vorágine de la historia, mientras que en la superficie ha aparecido una burbuja llena de vacío...; y, arrojados fuera de su mundillo se han encontrado encarados al mundo, un mundo ilimitado y por ello imposible de dominar.

(...) La pérdida de la patria no perturbará el orden interior sólo de aquellos cuya patria sea el mundo. La historia contemporánea ha resultado ser demasiado violenta y demasiado ilimitada para las literaturas excesivamente nacionales y particulares.

Y ese exceso de libertad es precisamente lo que más ata al escritor. Amenazados por la inmensidad del mundo y el carácter definitivo de sus problemas, se agarran desesperadamente al pasado; se agarran a sí mismos; desean quedarse tal como eran; tienen miedo del más íntimo cambio en sí mismos por temor a que todo se desmorone; y finalmente se agarran con desespero a la única esperanza que les queda, que es la esperanza de recuperar a la patria. (Gombrowicz, 2005. pp. 70-71)

No hay dudas de que para Gombrowicz el tema de la libertad es central, ya que le dedica mucho tiempo, páginas y reflexión a lo largo de toda su obra, tanto en el Diario, como también en sus novelas. De hecho, es un tema que podría asociarse estrechamente con uno de los tres conceptos que más interesaban a Gombrowicz: la forma (Gómez, 2006). El "exceso de libertad es precisamente lo que más ata al escritor" implica que para que un autor pueda desarrollarse, necesita límites, preocupaciones, problemas. Es decir: necesita la falta, las formas. Cuando tiene todo para crecer, para escribir, el escritor pierde su razón de ser, sus motivaciones. Y por eso debe buscar, cueste lo que cueste, la manera de encontrar obstáculos que le permitan volver a su cauce. Esos obstáculos pueden ser el exilio, los enemigos, el ridículo, las provocaciones; no importa en realidad qué, con tal de que aparezcan, que existan.

Con todo, el artista en el exilio, obligado a vivir no solamente fuera de la nación, sino también fuera de la elite, se encuentra de un modo mucho más directo con la esfera espiritualmente e intelectualmente inferior, nada lo aísla de ese contacto, tiene que soportar personalmente la presión de la vida inmadura.

(Gombrowicz, 2005, p. 71)

Si un lector llegara por primera vez a Gombrowicz y leyera esto, posiblemente habría una inmediata acusación de eurocentrismo, además de soberbia desmedida. Es muy probable que eso esté presente, pero lo que este polaco quiere transmitir es otra cosa. Para empezar, la "vida brutal e inmadura" no es para él una adjetivación 
peyorativa, sino todo lo contrario. De hecho, la inmadurez es otro de sus conceptos favoritos, y en él (y en el de la juventud) funda la mayor parte de su obra. La inmadurez no es una carga negativa, como sí ocurre históricamente. Gombrowicz es un ferviente adorador de la juventud inmadura (García, 1992); ve en ella algo positivo, probablemente lo único positivo puro del ser humano. Y no sólo lo aborda en su obra, sino que también lo aplica rigurosamente en su vida. El ejemplo más claro de esto puede verse en sus círculos de amistades. Gombrowicz detestaba las reuniones con editores, literatos, periodistas y grandes personalidades, y en cambio disfrutaba los encuentros con los jóvenes más irreverentes, tanto en Buenos Aires, como Santiago del Estero, Goya o Tandil (Pasolini, 2003).

\section{La provocación de Cioran}

Hasta aquí vimos algunos fragmentos de la respuesta que Gombrowicz escribe para discutir con Cioran. Es una carta que, en el Diario, ocupa cuatro páginas. Bastante para una epístola que tiene como propósito refutar una idea, para debatir con un intelectual que probablemente no tenga ni siquiera noción de la existencia de este polaco en Buenos Aires. ¿Por qué Gombrowicz lo toma como algo tan personal? ¿Por qué tanto afán en polemizar en algunos puntos que parecieran minúsculos, en comparación de otros grandes debates de la época? ¿Por qué sacar a colación tantos elementos que, pareciera evidente, son de su propia vida? Para responderlo, voy a permitirme citar en extenso algunos de los fragmentos del texto escrito por Cioran, ese que Gombrowicz leyó. Así comienza el rumano:

Es equivocado hacerse del exilado la imagen del que abdica, se retira y se oculta, resignado a sus miserias, a su condición de desecho. Al observarlo, se descubre en él un ambicioso, un decepcionado agresivo, un amargado que, además, es un conquistador. Cuanto más desposeídos estamos, más se exacerban nuestros apetitos y nuestras ilusiones. Incluso discierno alguna relación entre la desdicha y la megalomanía. El que lo ha perdido todo conserva, como último recurso, la esperanza de la gloria o del escándalo literario. Consiente en abandonarlo todo, salvo su nombre. Pero ¿cómo impondrá su nombre, si escribe en una lengua que los civilizados ignoran o desprecian?

¿Intentará otro idioma? No le será fácil renunciar a las palabras en las que perdura su pasado. Quien reniega de su lengua para adoptar otra, cambia de identidad, léase de decepciones. Heroicamente traidor, rompe con sus recuerdos y, hasta un cierto punto, consigo mismo.

Fulano escribe una novela que, de un día para otro, lo hace célebre. Cuenta en ella sus sufrimientos. Sus compatriotas, en el extranjero, sienten celos de él: ellos también han sufrido, y quizá, más. Y el apátrida se convierte o aspira a convertirse en novelista. Resulta una acumulación de zozobras, una inflación de horrores, estremecimientos que aviejan. No se puede renovar el indefinidamente infierno, cuya característica propia es la monotonía, ni tampoco el rostro del exilio. Nada exaspera tanto en literatura como lo terrible; en la vida, es demasiado evidente como para que se repare en él. Pero nuestro autor persiste; por el momento, oculta su novela en el fondo de un cajón y espera su hora. La ilusión de una sorpresa, de un renombre que se resiste pero que da por descontado, le sostiene; vive de la irrealidad. Tal es, sin embargo, la fuerza de esta ilusión que, si trabaja en una fábrica, lo hace con la idea de ser arrancado de ella un día por una celebridad tan súbita como inconcebible." (Cioran, 1973, p. 25)

Hasta aquí, pareciera que Cioran sí está hablando de Gombrowicz. Que lo conoce, que sabe de su experiencia, que pasó un buen tiempo con él y decidió hablar de su vida y obra, aunque sin citarlo. Eso no ocurrió, por supuesto, y obviamente hay detalles que no coinciden con la realidad de Gombrowicz. Pero esto puede ayudar a entender su reacción, su ímpetu al meterse de lleno en ese debate, que no prosperó. Cioran 
no habla de Gombrowicz, sino de muchos otros escritores que, al igual que este, atraviesan por experiencias muy similares y las elaboran de modos realmente parecidos. No caben dudas de que otros escritores tomarán las cosas de otra manera, actuarán diferente, se escaparán de esa caracterización prejuiciosa (pero no por eso incorrecta) que plasma Cioran. Pero es por lo menos llamativo que en su generalización haya tantos elementos que coincidan con lo vivido por Gombrowicz, uno más entre tantos literatos que abandonaron su país en esa época.

La visión de Cioran sobre los exiliados es extremadamente cínica, escéptica, pesimista, algo que no debiera sorprender a nadie que conozca mínimamente su obra y su pensamiento con respecto a muchos otros temas. Pero no por eso deja de ser interesante analizarlo, por lo menos desde el momento en que Gombrowicz se hace eco de esa mirada, responde a ella, le da una entidad. Cioran no ve a los exiliados como pobres hombres resignados, que abdicaron y aceptaron su "condición de desecho" (término muy fuerte, con mucha carga simbólica negativa). Al contrario, los define como ambiciosos, decepcionados, agresivos, amargados y, no por eso menos conquistadores. La idea de que "Cuanto más desposeídos estamos, más se exacerban nuestros apetitos y nuestras ilusiones" es absolutamente pertinente cuando estudiamos a Gombrowicz, cuando releemos sus respuestas a esta carta, cuando analizamos la progresión de su pensamiento, de sus ideas. ¿No es precisamente esto lo que él reafirma cuando sostiene que es necesario que el escritor abandone cualquier vestigio de comodidad para poder crear? ¿No es eso lo que dice cuando, categórico, insiste en que es vital que un autor pierda todo y caiga, para poder decir algo verdadero? Que Cioran intuya una relación entre desdicha y megalomanía es totalmente acertado, por lo menos en esta situación, en la que el sujeto goza con su sufrimiento, en la que halla placer en su displacer.

Y ese mismo hombre, dice el rumano, encuentra como una de sus últimas esperanzas de gloria el escándalo literario. ¿No es Gombrowicz un calco de esta definición? ¿No fueron escandalosas sus presencias desde los primeros años en Argentina? ¿No desentonó, desde el primer momento, con todos los grupos literarios consolidados que se habían formado en el país? ¿No fue al choque, de manera directa y premeditada, con todo el grupo Sur, y en especial con Borges? (Gasparini, 2007) Gombrowicz era un desubicado, estaba fuera de lugar, y aprovechaba esa posición para hacer visible, para hacer de la incomodidad una forma de vida, un mecanismo de subsistencia y de pública exposición (Hochman, 2008). "Consiste en abandonarlo todo, salvo su nombre". ¿No es precisamente esa la vida de este sujeto? Abandonó en Polonia una historia, un territorio y una lengua. Dejó amigos, posición social, comodidades económicas y hasta una fama adquirida que iba en aumento en la vieja Europa, el único lugar en el cual podía llegar a triunfar un hombre como él. Lo dejó todo, excepto su nombre, que lo acompañó toda su vida. Gombrowicz fue Gombrowicz en Polonia y en Argentina; lo siguió siendo cuando regresó a Europa, primero a Alemania y luego a Francia, y continúa siéndolo en el siglo XXI, de un modo más cosmopolita, internacional, traducido a decenas de lenguas. Un nombre que es, además, un estilo, una marca, un adjetivo. Hay libros gombrowiczianos, situaciones gombrowiczianas, maneras gombrowiczianas de decir las cosas (Gombrowicz, 1972 y 1999). Lo gombrowicziano, podría decirse, es un recurso literario que marcó una época, un pequeño antes y después, y que no puede ser pensado sin el escándalo que acompañó a su creador, el tiempo y la sociedad en los que vivió.

Cioran habla también de la dificultad del idioma, que pareciera ser otro factor fundamental en la trayectoria de los escritores que se exilian en países cuya lengua es diferente (Steiner, 1973 y 1975; Podlubne y Giordano, 2000). En el caso de Gombrowicz, la barrera idiomática fue una enorme dificultad, que a la vez sirvió como propul sión mítica de su historia (Gasparini, 2010). Tal vez la mejor muestra de esto sea la traducción de Ferdydurke (Gombrowicz, 2003) al español (Piñera, 
1947; Rússovich, 1999), que no se hizo siguiendo ningún criterio tradicional, sino que consistió en largas reuniones, alrededor de una mesa de café, en las que participaban muchas personas a la vez (mozos incluidos), con el cubano Virgilio Piñera como presidente del comité de traducción.

Cioran se pregunta si, para triunfar, el escritor exiliado intentará otro idioma. La respuesta en este caso es que sí, y de un modo muy particular. Los procesos habituales de traducción incluyen por lo menos a dos sujetos: un autor, que escribe en una lengua determinada, y un traductor, que supuestamente conoce muy bien ese idioma, y mejor aún aquel al cual traslada el texto. Pero en el círculo gombrowicziano de Argentina nadie sabía polaco. O por lo menos, nadie a quien Gombrowicz quisiera incluir en la traducción de Ferdydurke. Por eso los largos debates en un bar, con varios actores opinando al mismo tiempo; por eso Gombrowicz traducía primero del polaco al francés, y luego, en este idioma (el más culto y respetado por aquellos intelectuales), se discutía la correcta traducción al español ${ }^{1}$.

Pero el proceso contó con otro elemento anómalo: el Ferdydurke en polaco es un libro en el que su autor introduce muchos neologismos, y eso también aparece en la versión argentina de la novela, bajo dos formas diferentes. Por un lado, la traducción más o menos leal al concepto original; es decir: de una palabra inventada en polaco, a otra, también inventada, en español. Pero además Gombrowicz intervenía activamente en la traducción, y muchas veces prefería incluir palabras hispanas que le gustaban mucho, pero que no tenían ninguna relación coherente con las oraciones en las cuales quedaban plasmadas $^{2}$. De este modo, la versión traducida en

1 "No existía ningún diccionario polaco-español. Era preciso no sólo traducir, sino además inventar palabras nuevas para encontrar el equivalente de las polacas. Me acuerdo de que discutimos durante tres horas acerca de la expresión 'matungos de tiro'.". (Testimonio de Humberto Rodríguez Tomeu, en Rita Gombrowicz, 2008, p. 90)

2 "En ocasiones Gombrowicz le tomaba gran afecto a una palabra española cuyo sentido no comprendía muy bien y la imponía porque su sonoridad o su fisonomía le parecían evocadoras...". (Testimonio de Adolfo de Obieta, en Rita Gombrowicz, 2008, p. 101)
1947 cuenta con neologismos, pero también con palabras descontextualizadas, fuera de lugar. Podemos explicar esto de dos maneras: una es que Gombrowicz buscaba que su texto resultara incómodo, molesto, que quien lo leyera experimentara esa desubicación que acompaña a las palabras que no están donde deberían; la otra, que Gombrowicz se reía de nosotros (y de él mismo), al convertir su obra maestra en un juego que va más allá de la experiencia literaria tradicional. Dice Virgilio Piñera:

Cuando el libro apareció, llovió sobre él el fuego graneado de los gramáticos. En general, tenían razón. Las objeciones de Sabato, de Capdevilla, y tantos otros, se fundamentaban en argumentos contundentes. No creo, sin embargo, que por haber empleado mal algunas palabras, o de haber tomado otras en una acepción bastante discutible, la traducción fuese absolutamente mala. Sin que pretenda justificar esas faltas lo cierto es que tales errores se debieron a que fue imposible, en vista a la inminente aparición del libro, hacer una revisión al microscopio. Yo no creo, sinceramente, que a pesar de que uno que otro adverbio haya sido mal empleado, o de que un sustantivo haya sido usado impropiamente, la versión española de Ferdydurke resultara ilegible. (Piñera, en R. Gombrowicz, 2008, pp. 85-86)

Si pensamos en todo esto, y volvemos a leer la pregunta de Cioran ("¿̇Intentará otro idioma?"), el asunto adquiere un nuevo sentido. Podemos decir que Gombrowicz sí intentó otro idioma, pero no ese en el que está pensando Cioran (el que pertenece al espacio al cual llega el exiliado), sino uno nuevo, uno que tomara elementos de diferentes lenguas, que incluyera lo lúdico, lo absurdo, que tuviera diferentes connotaciones al ser leído por un público, nuevo también.

El resto de los párrafos citados de Cioran es también sumamente pertinente: el exiliado que cuenta su experiencia en una novela, el sufrimiento que hay en ella, la acumulación de zozobras, el enojo de sus compatriotas, el éxito que 
implica, todo eso está en la primera novela de Gombrowicz en Argentina: Trans-Atlántico (Gombrowicz, 2004). "La ilusión de una sorpresa, de un renombre que se resiste pero que da por descontado, le sostiene; vive de la irrealidad. Tal es, sin embargo, la fuerza de esta ilusión que, si trabaja en una fábrica, lo hace con la idea de ser arrancado de ella un día por una celebridad tan súbita como inconcebible". Todo eso también está en su vida: las horas perdidas en el banco polaco, la fantasía de triunfar cuando nadie apostaba por él, la idea de una grandeza no reconocida en Argentina y mal vista en Polonia. Gombrowicz pareciera seguir al pie de la letra la caracterización que Cioran hace de los escritores exiliados en general. Y es entendible que eso despierte su enojo, sus ganas de responder con vehemencia a ese artículo, que pone en juego emociones muy íntimas, además de una imagen pública con la que, está claro, Gombriwicz se identifica de inmediato. Siente el vértigo que implica enfrentarse con sí mismo.

Dice Cioran, en ese mismo artículo, que "Bajo cualquier forma que se presente, y sea cual sea su causa, el exilio, en sus comienzos, es una escuela de vértigo. Y el vértigo no es cosa a la que a cualquiera le sea dada la suerte de llegar." (Cioran, 1973, p. 26). La idea es sugerente, sobre todo si pensamos el vértigo como lo entiende Milan Kundera en La insoportable levedad del ser:

Aquel que quiere permanentemente 'llegar más alto' tiene que contar con que algún día le invadirá el vértigo. ¿Qué es el vértigo? ¿El miedo a la caída? ¿Pero por qué también nos da vértigo en un mirador provisto de una valla segura? El vértigo es algo diferente del miedo a la caída. El vértigo significa que la profundidad que se abre ante nosotros nos atrae, nos seduce, despierta en nosotros el deseo de caer, del cual nos defendemos espantados." (Kundera, 2003, pp. 66-67)

\section{Conclusiones: las consecuencias del vértigo}

Si el exilio es una escuela para el vértigo, y este es el miedo ante el deseo de caer, entonces Gombrowicz aprendió muy bien lo que podía sig- nificar esa caída. Treinta fueron los años que duró ese aprendizaje; catorce los que llevaba transcurridos cuando le escribe a Cioran para responderle que él puede estar en lo correcto en muchas cosas, pero que las generalizaciones jamás llegan a ser tan abarcativas como para transformarse en verdades universales. Por lo menos, no verdades que expliquen lo complejo de la experiencia humana, esa que él conoce tan bien, internado como está en sus contradicciones más exasperantes. Al respecto, más Cioran, para terminar:

Un peligro amenaza al poeta desarraigado: adaptarse a su suerte, no sufrir más por su causa, complacerse en ella. Nadie puede salvar a la juventud de sus zozobras pero se desgastan. Lo mismo sucede con la añoranza del terruño, con toda nostalgia. Los pesares pierden su lustre, se marchitan y, a pesar de la elegía, caen pronto en el abandono. ¿Qué hay entonces de más normal que instalarse en el exilio, Ciudad de Nada, patria invertida? En la medida en que se deleita en él, el poeta dilapida la materia de sus emociones, los recursos de su desdicha, como su sueño de gloria. Como la maldición de la que sacaba orgullo y provecho ya no le abruma, pierde, con ella, la energía de su excepción y las razones de su soledad. Expulsado del infierno, intentará en vano volver a instalarse en él, sumergirse en él de nuevo: sus sufrimientos excesivamente amortiguados le volverán indigno de ello para siempre. Los gritos de los que antaño estaba tan orgulloso se han vuelto amargura, y la amargura no se transforma en versos: ella le llevará fuera de la poesía. No más cantos ni más excesos. Una vez cerradas sus llagas, en vano hurgará en ellas para extraer algunos acentos: en el mejor de los casos, será el epígono de sus dolores. Le espera una decadencia honrosa. Falta de diversidad, de inquietudes originales, su inspiración se seca. Pronto, resignado al anonimato y como intrigado por su mediocridad, adquirirá la máscara de un burgués de ninguna parte. Helo ahí en el término de su carrera lírica, en el punto más estable de su desclasamiento." (Cioran, 1973, p. 26) 
Es claro que esa perspectiva es la que más espanta a Gombrowicz: la de perder la juventud, adaptarse, no sufrir, quedarse en la nostalgia y no poder ir más allá. Tal vez por eso la carta. Tal vez, por eso mismo, su vida, como una demostración obstinada de todo aquello a lo que estaba dispuesto, con tal de no ser catalogado como esos exiliados de los que habla Cioran. Un debate que no prosperó, que no llegó a ser, pero que, sin embargo, estaba latente, como sutil muestra de lo que la época dejaba entrever, en esas brechas de lo cotidiano.

\section{Bibliografía}

\section{Fuentes primarias}

Cioran, É. (1973). La tentación de existir. Madrid: Taurus.

Gombrowicz, R. (2008). Gombrowicz en la Argentina. Buenos Aires: El Cuenco de Plata.

Gombrowicz, W. (1972). Autobiografía sucinta. Barcelona: Anagrama.

Gombrowicz, W. (1997). Curso de Filosofía en seis horas y cuarto. Barcelona: Tusquets.

Gombrowicz, W. (1999). Cartas a un amigo argentino. Buenos Aires: Emecé.

Gombrowicz, W. (2003). Ferdydurke. Buenos Aires: Seix Barral.

Gombrowicz, W. (2004). Trans-Atlántico. Buenos Aires: Seix Barral.

Gombrowicz, W. (2005). Diario. 1953-1969. Buenos Aires: Seix Barral.

Piñera, V. (1947). "Witold Gombrowicz: Ferdydurke". En Realidad, año 1, Vol: 1, No: 3, pp. 469-471.

\section{Fuentes secundarias}

Castillo, A. (2010) Desconsideraciones. Buenos Aires: Seix Barral.
García, G. (1992). Gombrowicz, el estilo y la heráldica. Buenos Aires: Atuel.

Gasparini, P. (2007). El exilio procaz: Gombrowicz por la Argentina. Rosario: Beatriz Viterbo.

Gasparini, P. (2010). "La extraterritorialidad del pobre". En N. Hochman (ed.) Pensar el afuera (pp. 103-120). Mar del Plata: Kazak.

Grinberg, L. y R. (1984). Psicoanálisis de la migración y el exilio. Madrid: Alianza.

Hochman, N. (2011). "Exilio y paralaje". En Letras Históricas $\mathrm{N}^{\circ}$ 4, Universidad de Guadalajara, México, pp. 121-138.

Hochman, N. (2008). "Gombrowicz y la sujeción del sujeto". En Revista Kafka, Año 2, No 5, México, pp. 46-49.

Kundera, M. (2003). La insoportable levedad del ser. Buenos Aires: Tusquets.

Pasolini, R. (2003). "Ferdydurkistas en la pampa salvaje: Witold Gombrowicz en Tandil". En La escalera, Anuario de la Facultad de Arte, No 13, UNICEN, Tandil, pp. 87-108.

Podlubne, J. y Giordano, A. (2000). "Exilio y extraterritorialidad: Wilcock y Biancotti". En N. Jitrik (dir.), Historia crítica de la literatura argentina. Vol: 11 . La narración gana la partida (pp. 385-390). Buenos Aires: Emecé.

Rússovich, A. (1999, 25 de julio). "Gombrowicz y el castellano: el otro idioma de Witoldo". En Cultura y Nación, Suplemento Cultural de Clarín, Buenos Aires.

Schwarcz, J. A. (1999). "Consideraciones psicológicas en torno a la migración. El caso de Paul Zech". En Regula Rohland de Langbehn (ed.), Paul Zech y las condiciones del exilio en la Argentina, 1933-1946. Buenos Aires: UBA, FFyL.

Steiner, Georges (1973). Extraterritorialidad. Ensayos sobre la literatura y la revolución lingüistica. Barcelona, Barral.

Steiner, Georges (1975). Después de Babel. México: Fondo de Cultura Económica. 